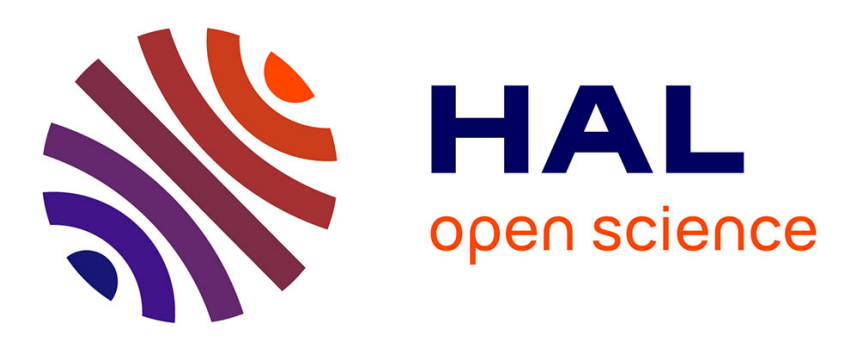

\title{
Impact assessment of new services in the Galapagos low voltage network
}

Diego X Morales, Yvon Bésanger, Carlos Álvarez Bel, Ricardo Medina

\section{To cite this version:}

Diego X Morales, Yvon Bésanger, Carlos Álvarez Bel, Ricardo Medina. Impact assessment of new services in the Galapagos low voltage network. Transmission \& Distribution Conference and ExpositionLatin America (PES T\&D-LA), 2016 IEEE PES, 2016, Morelia, Mexico. pp.1-6, 10.1109/TDCLA.2016.7805630 . hal-02330356

\section{HAL Id: hal-02330356 https://hal.science/hal-02330356}

Submitted on 19 Oct 2020

HAL is a multi-disciplinary open access archive for the deposit and dissemination of scientific research documents, whether they are published or not. The documents may come from teaching and research institutions in France or abroad, or from public or private research centers.
L'archive ouverte pluridisciplinaire HAL, est destinée au dépôt et à la diffusion de documents scientifiques de niveau recherche, publiés ou non, émanant des établissements d'enseignement et de recherche français ou étrangers, des laboratoires publics ou privés. 


\section{Impact Assessment of New Services in the Galapagos Low Voltage Network}

D. X. Morales,

Member IEEE,

Ecuador

Diego.Morales-Jadan@g2elab.grenoble-inp.fr

\author{
Y. Besanger, \\ Senior Member, IEEE, \\ France
}

Yvon.Besanger@g2elab.grenoble-inp.fr

\author{
C. Alvarez Bel \\ Member IEEE, \\ Spain \\ CALVAREZ@upvnet.upv.es
}

\author{
R.D. Medina \\ Member IEEE, \\ Ecuador \\ rmedinav@ups.edu.ec
}

\begin{abstract}
The Galapagos Islands are a fragile ecosystem which belongs to Ecuador. About 26.000 people are located in four islands of the archipelago and $60 \%$ of the population is concentrated on Santa Cruz Island. Combined technologies are used for providing electricity such as thermal, photovoltaic and wind. The government of Ecuador is fostering the policy zero CO2 emissions within the islands. In order to achieve this objective, some initiatives are carried out like replacing the conventional vehicles by electrical ones and the gas stoves by induction ones. Taking into account this framework, it becomes vital to assess the impact of these new policies on the distribution network; for sure, this will change significantly the operation and control of Galapagos distribution grid. Hence, strong integration of distributed generation, electric vehicles, and induction cookers must be assessed at the low voltage level, where they are usually connected.

This paper assesses the impact of all the new services on the low voltage network as well as the new electric demand due to natural population grow. Real field information has been used in the models presented
\end{abstract}

Index Terms - LV network, electrical vehicles, induction cookers, Distributed Generation, impact study.

\section{INTRODUCTION}

$\mathrm{I}$ $\mathrm{n}$ the context of transformation of traditional power grids to next generation grids or Smart Grids $(S G)$, the first great change is occurring in distribution networks, since distribution networks are the connection point between new agents with the grid. The Ecuadorian electrical sector is aligned with new concepts like distributed generation $(D G)$ such as micro and pico hydraulic, photovoltaic, wind and biomass, and new loads such as electric vehicles $(E V)$ and induction cookers. The induction cooker is a specific new load in Ecuador, which has been recently deployed into the $\mathrm{LV}$ grid to replace gas stoves. Already have been deployed 187280 induction cookers in Ecuador, and for the specific case of Galapagos Archipelago nowadays are 80 already connected and 240 have been requested [1].

The Ministry of Electricity and Renewable Energy of Ecuador is analyzing the possibility to incorporate devices with the ability to measure and control these new loads. Hence, Advanced Metering Infrastructure (AMI) technology would collaborate to perform demand side management $(D S M)$ and

This work was partially supported by Energy Research Team at Universidad Politécnica Salesiana (UPS), Cuenca - Ecuador. to improve agents visibility in the network [2].

In Addition, it is worth to mention that the population in the Galapagos Islands is 25124 people [3]. There are 14 islands in the archipelago and all of them are Natural World Heritage. For this reason, the government has launched the initiative zero $\mathrm{CO} 2$ emissions in order to support the nature preservation, thus, the conventional vehicles must be changed by electrical ones. Also, there is much support to integrate clean energy like photovoltaic. One of the main statements within $S G$ concepts is the evolution of a passive towards active client, known as prosumer (proactive consumer) [4]. Accordingly, encourage customers for generating their own energy is a key aspect considered within the new policies to convert Galapagos to an archipelago energetically selfsustaining.

The advent of all these challenges must be evaluated in order to measure their impacts on the electrical network. All the policies are looking for a better life quality in Galapagos, but if the impacts of new services are not managed suitably, this could bring to worst results, for instance, explosion of transformer due to overloads, higher frequency of outages, loss of reliability, and so on. Thus, realistic simulations are necessary to build a common understanding of the functions of a $S G$ [5] in the specific case of Galapagos. These simulations also should seek to identify the impact on the grid of a high penetration of distributed generation like photovoltaic, which may cause bidirectional flows [6], and $E V$ that usually represents a significant load, it is worth to mention normally the maximum number of clients per transformer is 40. In [7], we can see how demand response can contribute to the better integration of renewable energy resources such as wind power, solar, small hydro, biomass and CHP.

\section{MODELING OF ELECTRIC NETWORK}

The first step involves modeling different elements of the grid such as lines, conductors, transformers, loads [8] and unconventional elements e.g.: photovoltaic panels, smart buildings including induction cookers, $E V$ and domestic wind turbines or photovoltaic arrays. All these elements were modeled following the methodology described in [9]. Also, in [10], we can find details about the need to consider the mutual effects between the lines in unbalanced networks. Hence, it is essential to model all the lines considering the neutral wire. The Matlab/Simulink environment has been used to model all the mentioned elements and for performing the simulations. 


\section{A. Transformer}

The Galapagos power system is mainly three-phase at the medium voltage (MV) level. Then, pole-mounted MV/LV transformers distribute electric power to end-users. On the LV side of the transformer, a single-phase three-wire supply provides electricity at $120 \mathrm{~V}$ and $240 \mathrm{~V}$ levels, as shown in Fig. 1.

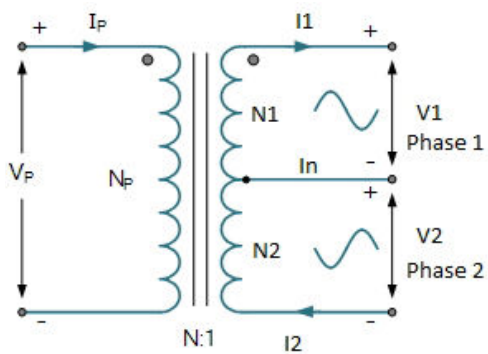

Fig. 1. Equivalent circuit for Centre Tapped Transformer

The Galapagos network is basically equivalent to the North American networks topologically [11], the parameters of the transformer model can be found in [9].

\section{B. $P V$}

PV sources could be modeled taking into account different approaches ; for instance, in [12] the PV model consider the single-diode five-parameters model. In [13] the block "three phase dynamic load" fed with a negative profile is used. For our studies, this last approach has been selected since this article seeks to evaluate the PV impact on the network and several PV curves from real measurements are available. The month with highest consumption during the year in Galapagos is March. Therefore, the active power measures of March of the existing PV power plant of $1500 \mathrm{~kW}$ installed at Santa Cruz Island are used in order to create 40 individual PV curves for the end-users. Basically, the existing curves were transformed to per unit system, after that these ones were multiplies by the rated power desired. The next figure show the obtained PV profiles

40 Individual Solar Curves

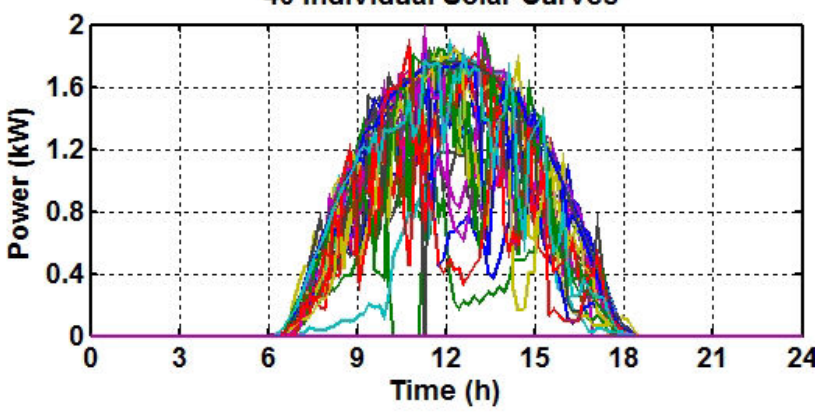

Fig. 2. PV profiles

According to [14], the energy resources in Santa Cruz island are enough to satisfy the end-user's average consumption. This resources even could generate $25 \%$ additional power. In order to achieve the above mentioned, it is necessary to install $2150 \mathrm{Wp}$ at the roof of client's household. For reaching $2150 \mathrm{Wp}$ is necessary to build a PV array composed by some PV panels.

\section{Electrical Motorbikes}

The government of Ecuador desires to replace the conventional vehicles (fuel oil) by ecological and more efficient ones. Hence, a policy has been implemented to promote the massive change towards electrical vehicles. A model of electrical motorbike taken from [14], with rated power of $1000 \mathrm{~W}$ will be used in this paper. This model is a stochastic profile created upon a Monte Carlo Simulation. The maximum power is $630 \mathrm{~W}$ (see Figure 3).

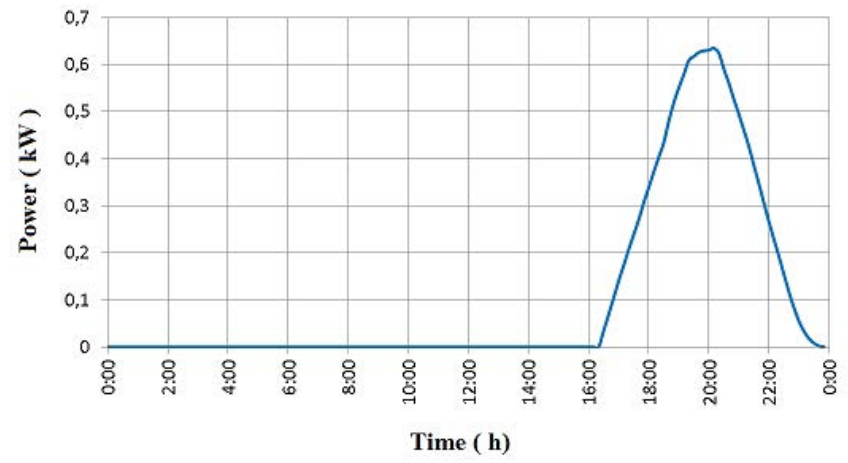

Fig. 3. Electrical Motorbike average curve

This average profile will be combined with a coincidence factor, which is function of client's number [15]. The coincidence curve is defined in [14]. It is worth to mention that the electrical motorbikes, when charging, are connected to $240 \mathrm{~V}$ (phase-to-phase).

\section{Loads}

In Galapagos exists different types of clients, normally most of them are residential; a typical residential client has different appliances such as refrigerator, television, washing machine, microwave and lighting. The Galapagos Utility makes regular measuring campaigns. Therefore, there are available real load curves concern both the active and reactive power with 10 minutes samples [16]. Most loads are connected to $120 \mathrm{~V}$ (phase-to-neutral), then, a random repartition of the 40 loads between phase 1 and 2 has been made.

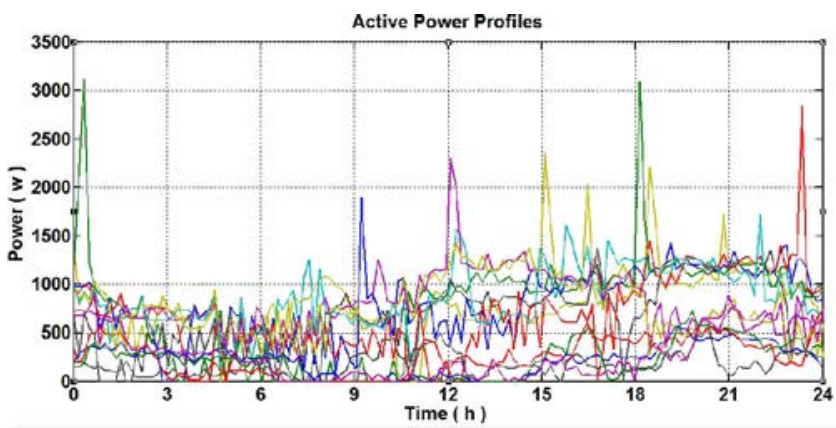

Fig. 4. Active Power curves measured at end users. 


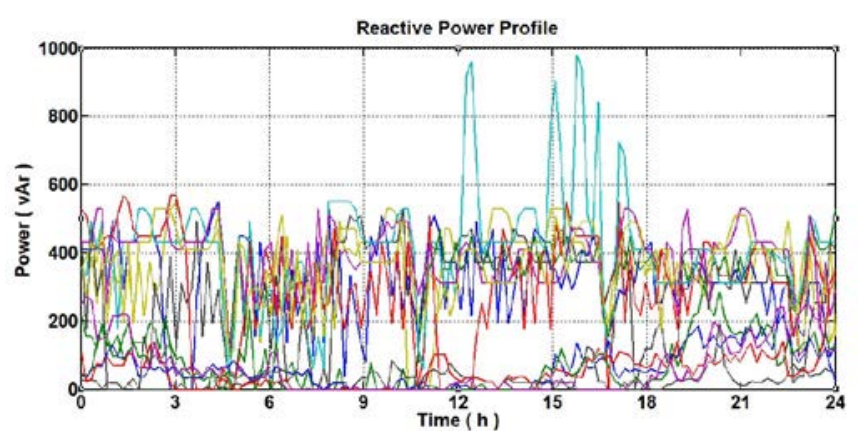

Fig. 5. Reactive Power curves measured at end users.

The approach that consider to use real curves is much better than one which consider an average curve [15]. Although obviously it is more complicated due to $i$ ) Usually the utilities has not real residential curves ii) It is needed a higher computational effort.

\section{E. Induction Cookers}

In Ecuador, especially in Galapagos, there are several policies that foster the change of conventional stoves by induction ones. The induction cooker rated power is typically in the range $2500-7000 \mathrm{~W}$. The voltage level is $240 \mathrm{~V}$. Real measurements are used in order to feed the induction cooker model. The next figure show 40 induction cooker profiles, in this section also is assumed that the end-user has only induction cookers connected to the grid.

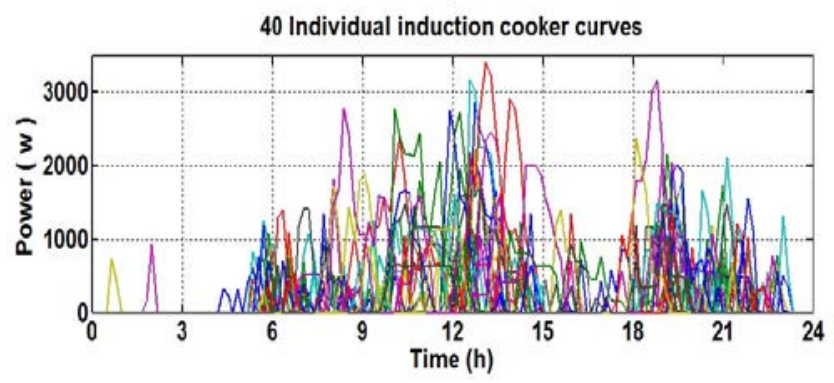

Fig. 6. Induction Cooker profiles

\section{STUDY CASE}

\section{A. Description of the study}

Santa Cruz Island has three MV feeders at $13.8 \mathrm{kV}$, which are composed of three and single phase sections. The purpose of this paper is to evaluate the impact of new services at the LV level. Therefore a MV/LV transformer with its network should selected for the study. Hence, the information within the Geographical Information Systems (GIS) has to be taken into account. First of all, the MV feeder 1 is chosen due to its residential characteristics. After that, a statistical analysis has been performed on its LV sub-networks. Through the GIS's own tools, a summary about the transformers with their number of clients has been made. Transformers with only one client were not taken into account. Once performed, 36 $\mathrm{MV} / \mathrm{LV}$ transformers remain, and the minimum number of clients per transformer is 2 and the maximum 40 , the mean is approximately 17 and the standard deviation is 11.19 clients per transformer. Fig. 7 shows the frequency distribution of clients per transformer; the highest distribution is 6 transformers with 10 clients. , the average capacity of transformers is $25 \mathrm{kVA}$. Taking into account that the maximum power in a typical residential client of Santa Cruz is 1559 VA, surely the transformer with 40 clients and capacity of $50 \mathrm{kVA}$ would have a considerable percentage of relative load.
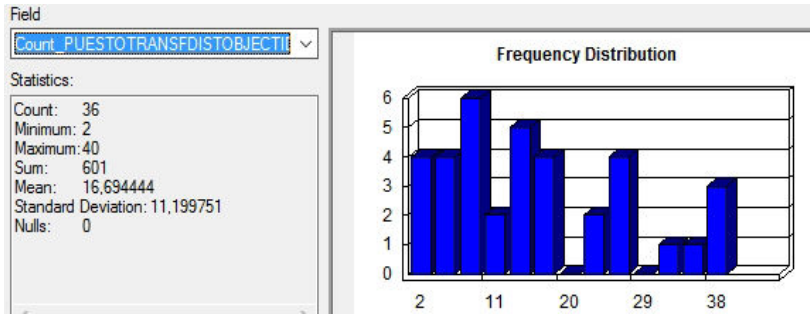

Fig. 7. Frequency Distribution of clients per transformer at Galapagos

Then, Table I shows the main characteristics of the selected LV network, which is shown in Fig. 8

TABLE I

DESCRIPTION OF THE MODELED LV NETWORK

\begin{tabular}{|c|c|c|c|c|}
\hline \hline Substation & Transformer & Power (KVA) & Customers & Nodes \\
\hline Santa Cruz & TR1 & 50 & 40 & 15 \\
\hline
\end{tabular}

TYPICAL LV NETWORK - SANTA CRUZ GALAPAGOS

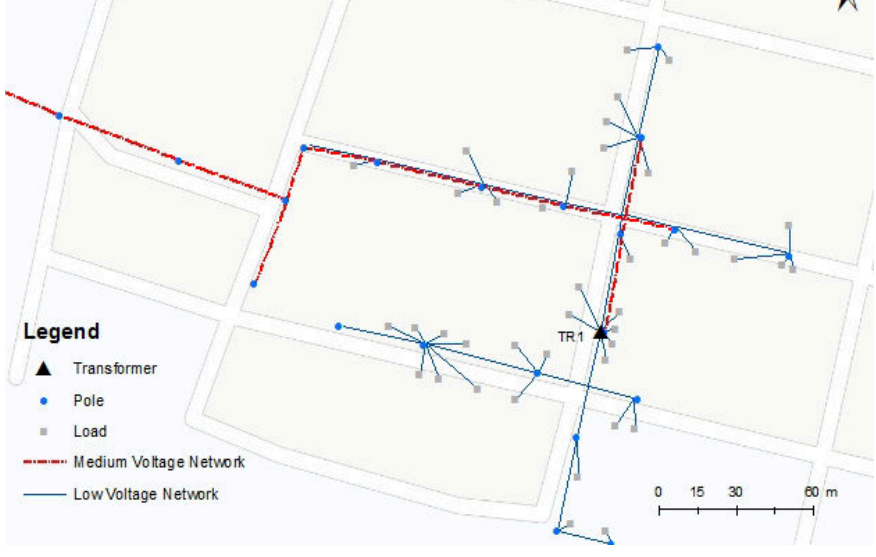

Fig. 8. LV Network modeled into Simulink

\section{B. Scenarios}

In order to assess the impact of the new loads on the LV grid, some scenarios are defined. For each scenario, the voltages, power and currents are analyzed. Also, another scenario including PV panels connected at end-user level is analyzed as a first attempt to reduce overloads. The nomenclature is:

$\mathrm{PQ}=$ Load fed with Active and Reactive power curves.

$\mathrm{IC}=$ Induction Cooker

$\mathrm{EM}=$ Electrical Motorbike

$\mathrm{G}=$ Growing of population, therefore of the load. 


\section{1) Scenario $P Q$}

This scenario represents the current situation (reference case) of the selected LV network. Only the active and reactive load curves are considered.

\section{2) Scenario $P Q+I C$}

Once modeled the LV network, and considering the policies described in the section II, an induction cooker is implemented for each residential client, in order to assess the impact of IC on the grid variables.

\section{3) Scenario $P Q+I C+E M$}

An electrical motorbike for each client is added to the previous scenario.

\section{4) Scenario $P Q+I C+E M+G$}

This scenario considers an annually growing due to growth population rate leading to a $8,5 \%$ increase of the load [17]. This value is higher than growth population rate in the other provinces, due to the population has grown haphazardly mainly for the tourist activities. This growth has forced to increase the generation capacity and to deploy energy efficiency programs.

\section{5) Scenario $P Q+I C+E M+G+P V$}

In this scenario, assuming that the transformer will suffer overloads and taking advantage of the existence of solar resources, an array of PV panels [14] is connected in each client house to $240 \mathrm{~V}$. The next figure illustrates the scenario 5 , where all the new services are connected. PV and EM are modeled only with active power, assuming that their interface converter can tune a power factor equal to 1 .

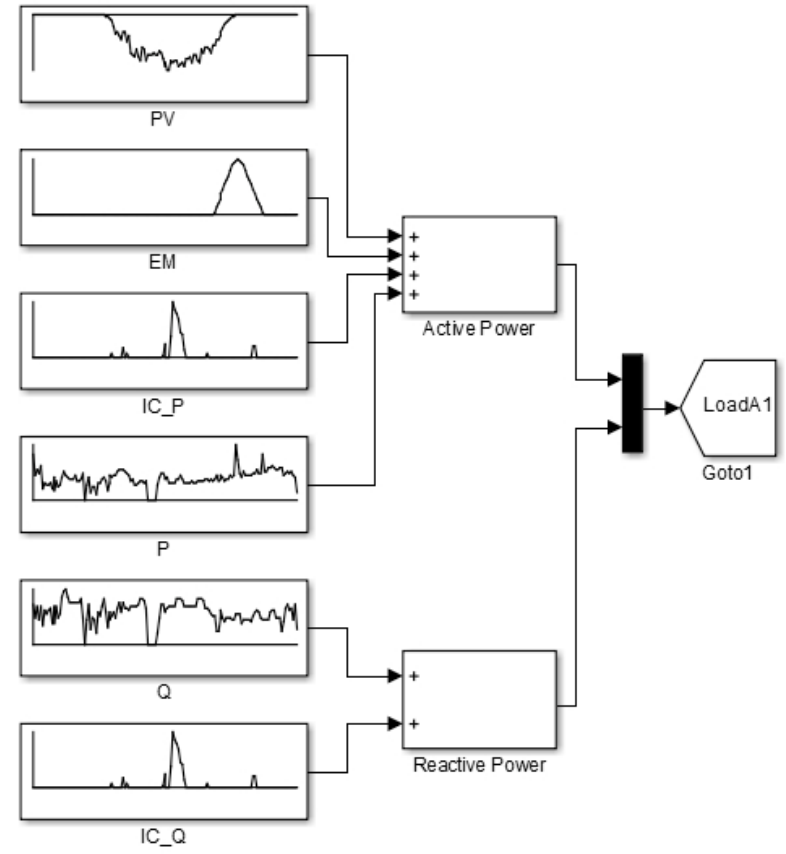

Fig. 9. Simulink model considering all the new services.

\section{Methodology}

In order to limit the overall simulation time of the different scenarios, a software interface between the GIS (named ARCMAP) and Matlab/Simulink has been developed. Basically, the logic consists in building the topology of the network inside the GIS (See Figure 10).

Afterwards, by means of code developed in Matlab, the Simulink model is created automatically with all the connections between the elements. It is worth noting that, also, the technical information requested by Simulink is calculated in the script.

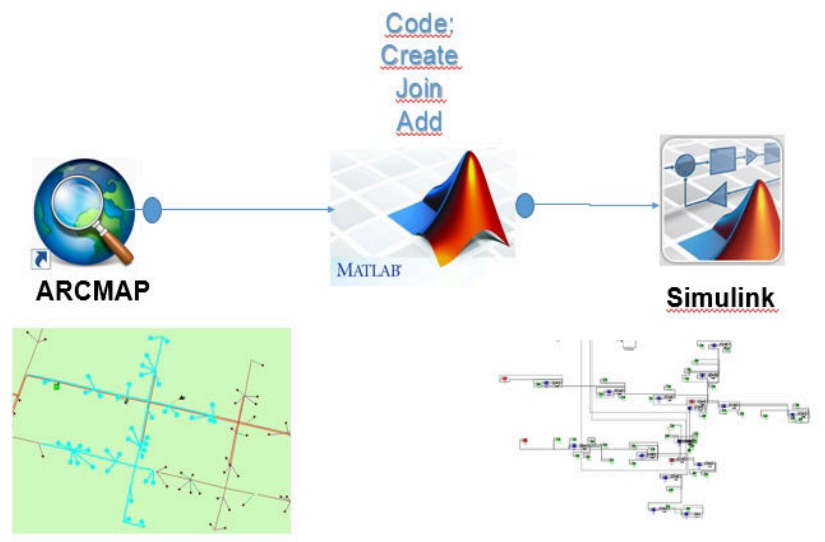

Fig. 9. Interface between ARCMAP and Matlab/Simulink

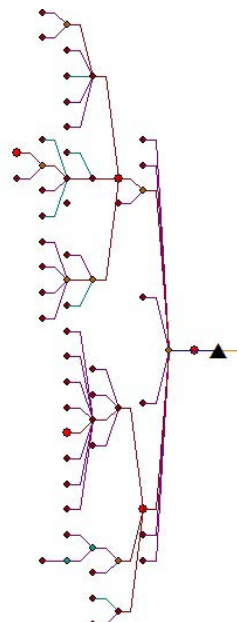

Fig. 10. Topology of LV Network created into GIS

\section{RESULTS}

In the first scenario, the maximum power occurs at 20:48 and its value is $36,94 \mathrm{kVA}$. Regarding the drop voltage standard (limits of $+/-5 \%$ of the nominal voltage) all the nodes are inside the margin. The maximum current through the transforms is $147,09 \mathrm{~A}$, and the minimum voltage is $233,40 \mathrm{~V}$ (phase-to-phase). As expected, a current flowing through the neutral wire exits, the maximum value is $27,06 \mathrm{~A}$. This confirms that the network is unbalanced (Fig. 11). 

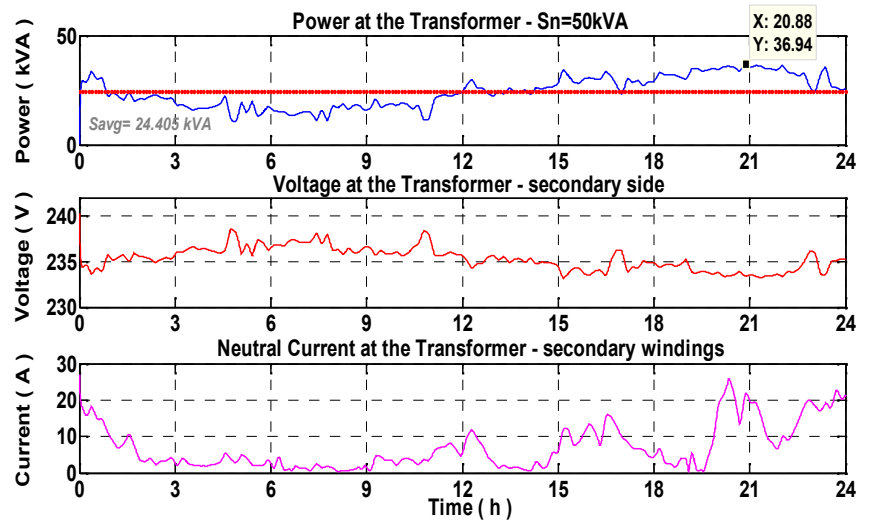

Fig. 11. Scenario PQ

The results of the second scenario shows an increase of 5,73 $\mathrm{kVA}$ in the average power. Now, the profile has 2 peaks during the day, the first one at 12:20 and the second one at 19:18. The peak in the night is higher and reaches a value of $56,05 \mathrm{kVA}$. The lowest voltage is $229,8 \mathrm{~V}$ (phase-to-phase). This scenario highlights overloads during the night and noon. However, voltages are still inside the standard limits (Fig. 12). The maximum value of neutral current is $28,15 \mathrm{~A}$.

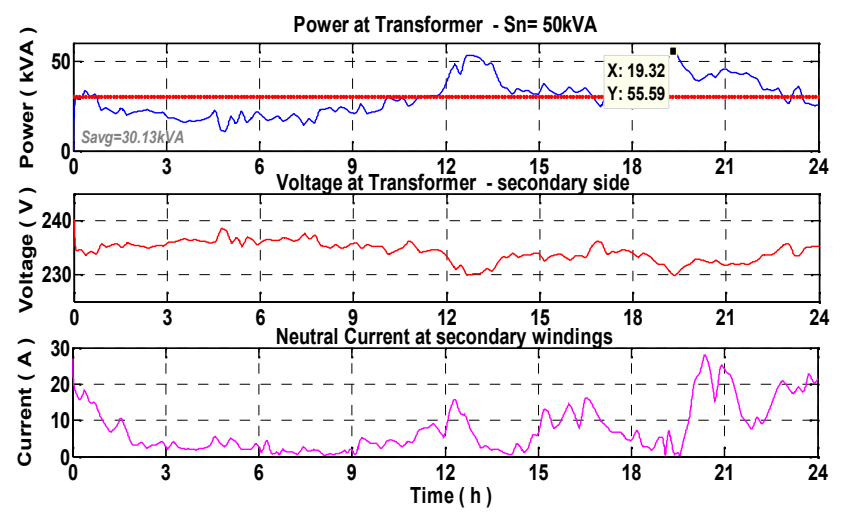

Fig. 12. Scenario PQ + IC

The scenario 3 shows an increase in the maximum power of $10,76 \mathrm{kVA}$, the second peak at the night is $66,81 \mathrm{kVA}$ at $19: 18$, the lowest voltage is $228,2 \mathrm{~V}$ (phase-to-phase) during a few minutes. The maximum value of neutral current is 30,09 A, which indicates that the imbalance is basically still equivalent to the scenario 1 and 2 . However, the maximum current in the transformer is $279,94 \mathrm{~A}$, almost twice than for scenario 1. This scenario highlights voltages outside the standard limits and a significant overload in the transformer with a $134 \%$ relative load during a few minutes (Fig. 13).
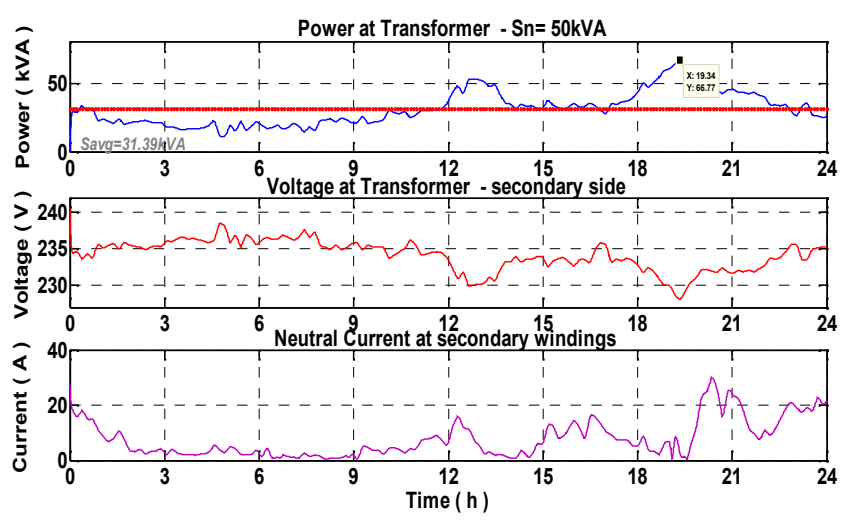

Fig. 13. Scenario $P Q+I C+E M$

The scenario 4 also considers a population growth. As expected, the power curve of the transformer has undergoes an increase and its average value is now $33,77 \mathrm{kVA}$ whereas the peak is $71,06 \mathrm{kVA}$. As in the scenario 3, voltages are outside the allowed limits, the minimum voltage is $227,2 \mathrm{~V}$ (phase-tophase). The maximum neutral current is $35,15 \mathrm{~A}$ and the maximum current trough the transformer is $298.18 \mathrm{~A}$. The relative load of the transformer reaches $142,12 \%$ as maximum during at least 30 minutes (Fig.14).

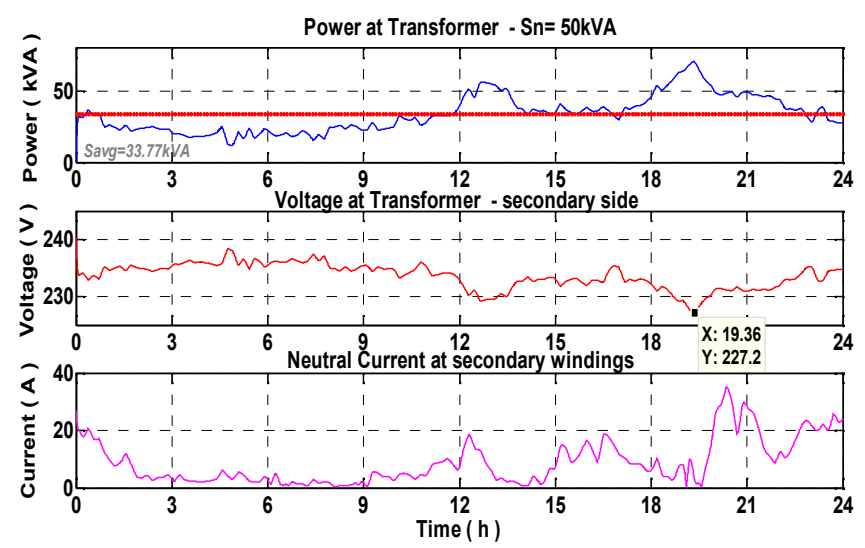

Fig. 14. Scenario $\mathrm{PQ}+\mathrm{IC}+\mathrm{EM}+\mathrm{G}$

The next figure shows a comparison between the powers in the transformer for the different scenarios. We can see that the scenarios that include EM and $\mathrm{G}$ are the more disfavoring. The peak in the night is the highest one in all of the cases.

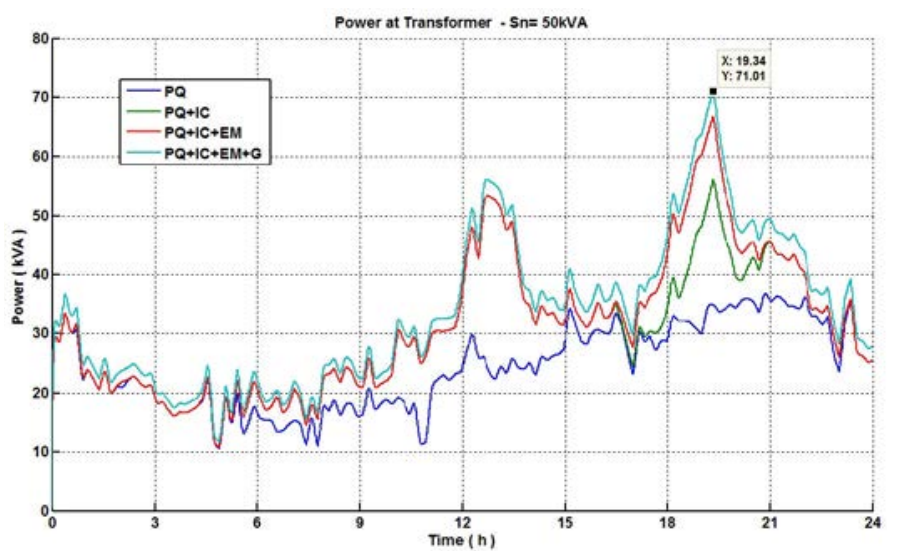

Fig. 15. Comparison between scenarios 
The final scenario assesses the insertion of PV sources in the end-user's facilities. The figure 2 depicted that the solar resources are available since 6:00 to 18:00 approximately. The installed PV panels are enough (in terms of produced power) to reverse the flow between 07:36 and 15:54. The average power in the transformer decreases considerably to 13,75 kVA. Despite the PV sources installation, we still have the power peak during the night for obvious reasons, and consequently, the voltage still crosses the lower limit during this peak. The maximum current flowing in the reverse sense is $122,44 \mathrm{~A}$, the imbalance is practically the same as in the scenario 4 (Fig. 16).

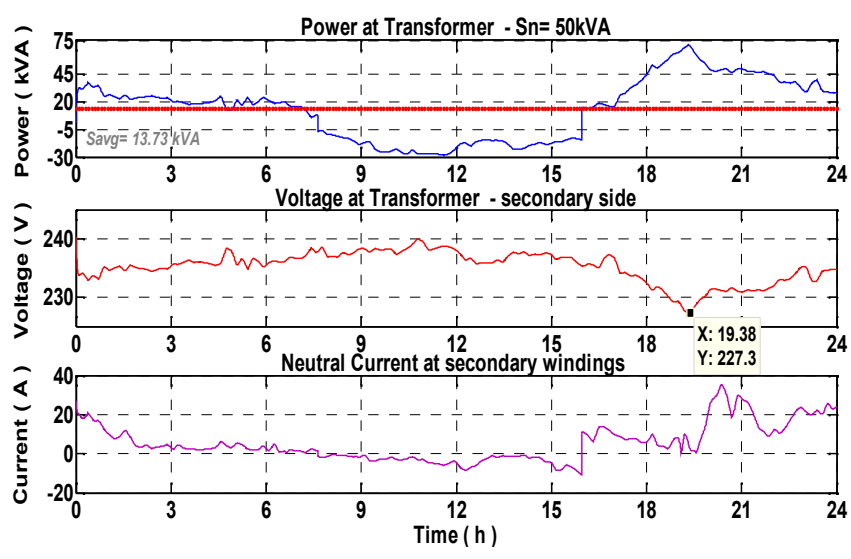

Fig. 16. PV scenario, where is possible to see the reverse flow.

\section{CONCLUSIONS}

In this paper, a study of the impact of new services which will be implemented soon in the Galapagos Islands has been carried out. Real data curves have been used such as residential load, PV production, and induction cookers, with a real part of LV Galapagos network, in order to make the simulations most realistic as possible. Normally, it is common to suppose that between midnight and 03:00AM the consumption is almost zero, however, as we can see in the results it does not happen in Santa Cruz, and therefore shift the EM load to this period is not convenient, in the other hand from 3:00 to 6:00 the consumption reaches its minimum, probably being a time to stimulate EM charging. A smart charging strategy must be analyzed in order to improve the management of new loads. This strategy could be based on the shift of groups of charging EM.

The EM and IC also could be connected at $120 \mathrm{~V}$, however it will not be a good solution because high power loads must be connected at the highest voltage available and the load unbalance in the center tapped transformer is a strong reason for this. Thus, the idea is to take advantage of the changes that are suffering the clients to change their supply to $240 \mathrm{v}$.

The next work will seek to develop smart strategies to avoid big overloads in the MV/LV transformer and keeping the voltages within the normal operation range. For example, the last scenario shows that a storage system could be interesting in order to store the energy when the energy is flowing in the reverse way and to supply it during the peak period. This will lead to a shave of this peak. Others smart strategies to develop could be the Voltage Var Control (VVC) using the reactive abilities of PV interface converter, and the Demand Side Management (DSM), which needs to implement some Smart Building/Home facilities such as energy boxes.

A powerful interface between GIS and Simulink has been developed to facilitate the carrying out of several analysis with different scenarios and topologies, and a Simulink library was created with new blocks for considering the Galapagos reality.

\section{REFERENCES}

[1] MEER, "Dashboard Cocinas de Inducción," in Ministry of Electricity and Renewable Energy of Ecuador, M. o. E. a. R. E. o. Ecuador, Ed., ed. http://gissigde.maps.arcgis.com/apps/dashboard/index.html\#/a84655ed31fc 407bb9afdfc0dae968c6, 2015.

[2] S. Huibin, S. Ying, and L. Wei-Jen, "A demand side management model based on advanced metering infrastructure," in Electric Utility Deregulation and Restructuring and Power Technologies (DRPT), 2011 4th International Conference on, 2011, pp. 15861589.

INEC. (2015). Ecuador en Cifras - Población y Demografia.

[4] G. Ritzer and N. Jurgenson, "Production, Consumption, Prosumption The nature of capitalism in the age of the digital 'prosumer'," Journal of consumer culture, vol. 10, pp. 13-36, 2010 .

[5] G. Feng, L. Herrera, R. Murawski, E. Inoa, W. Chih-Lun, P. Beauchamp, et al., "Comprehensive Real-Time Simulation of the Smart Grid," Industry Applications, IEEE Transactions on, vol. 49, pp. 899-908, 2013.

[6] P. Kotsampopoulos, V. Kleftakis, G. Messinis, and N. Hatziargyriou, "Design, development and operation of a PHIL environment for Distributed Energy Resources," in IECON 2012 38th Annual Conference on IEEE Industrial Electronics Society, 2012, pp. 4765-4770.

[7] L. Montuori, Alcázar-Ortega, M., Álvarez-Bel, C., Domijan, A., "Integration of renewable energy in microgrids coordinated with demand response resources: Economic evaluation of a biomass gasification plant by Homer Simulator," Applied Energy, vol. 132, 1 November 20142014.

[8] M. Kezunovic, "Teaching the smart grid fundamentals using modeling, simulation, and hands-on laboratory experiments," in Power and Energy Society General Meeting, 2010 IEEE, 2010, pp. $1-6$.

[9] D. Morales, Medina, R. ,Besanger Y. , "Proposal and Requirements for a Real-Time Hybrid Simulator of the Distribution Network " Chilecon-2015, 2015.

[10] J. Sifuentes, "Modélisation de réseaux de distribution dans un simulateur temps-réel pour des applications "Smart Grids »," STAGE PFE, Institut Polytechnique de Grenoble, 2013.

[11] A. Dubey and S. Santoso, "Electric Vehicle Charging on Residential Distribution Systems: Impacts and Mitigations," Access, IEEE, vol. 3, pp. 1871-1893, 2015.

[12] D. Sera, R. Teodorescu, and P. Rodriguez, "PV panel model based on datasheet values," in Industrial Electronics, 2007. ISIE 2007. IEEE International Symposium on, 2007, pp. 2392-2396.

[13] A. Mercier, "Pilotage de la production décentralisée et des charges non conventionnelles dans le contexte Smart Grid et simulation hybride temps réel. Energie électrique. ," PHD, G2ELab Laboratoire de Génie Electrique de Grenoble, Université Grenoble Alpes, hal.archives-ouvertes.fr, 2015.

[14] U. P. d. Valencia., "ANÁLISIS PARA LA IMPLEMENTACIÓN DE REDES INTELIGENTES EN ECUADOR ", Insituto de Ingeniería Energética, Universidad Politécnica de Valencia, 2015.

[15] W. H. Lee, Power Distribution Planning Reference Book vol. 2nd: Marcel Dekker, Inc., 2004.

[16] D. Morales, Medina, R., "Real-Time Hybrid Simulator of the Distribution Network for Smart Grid Applications," SICEL 2015, vol. 8, p. 4, November 20th, 20152015.

[17] ARCONEL. (2015). Estadisticas del Sector Electrico - Demanda Anual. 